\title{
An Intelligent Prenatal Screening System for the Prediction of Trisomy-21 Using Triple Test Variables: The Hacettepe System
}

\author{
Doruk Cevdi KATLAN", Atakan TANACAN, Gokcen ORGUL ${ }^{1}$, Kemal LEBLEBICIOGLU1, Mehmet Sinan BEKSAC ${ }^{1}$ \\ Ankara, Turkey
}

\section{ABSTRACT}

OBJECTIVE: To introduce an intelligent prenatal screening system, using triple test variables.

STUDY DESIGN: In this study, we have used a backpropagation learning algorithm (a supervised artificial neural network) to develop an intelligent antenatal screening system (heretofore referred as Hacettepe System). Triple test variables were used as input variables, while "Down syndrome" and "nonDown syndrome" fetuses were the output of the algorithm. Unconjugated estriol (E3), beta-human chorionic gonadotropin, and $\alpha$-feto protein with gestational week and maternal age (triple test) were used as input variables in the training and testing. Multiples of median values of the E3, $\alpha$-feto protein, and betahuman chorionic gonadotropin were used in this study.

The testing group of Hacettepe system consisted of 97 patients who were found to be high-risk (>1/250) during the routine antenatal screening (triple test) and underwent amniocentesis for fetal karyotyping.

RESULTS: Amniocentesis was performed in 97 pregnancies with "high-risk" triple test results $(>1 / 250)$. Fetal karyotyping revealed trisomy 21 in about 9.3\% (9/97) of the pregnancies. Our algorithm (Hacettepe System) detected $77.8 \%$ (7/9) of Down syndrome cases. Moreover, all of the normal fetal karyotypes were assigned as normal in the Hacettepe System.

CONCLUSION: We have developed an intelligent system using the backpropagation learning algorithm (using triple test variables) to predict trisomy 21.

Keywords: Antenatal screening, Artificial intelligent system, Neural networks, Prenatal diagnosis, Triple test

Gynecol Obstet Reprod Med 2019;25(2):67-69

\section{Introduction}

Prenatal screening (PS) is an essential part of the antenatal care programs worldwide $(1,2)$. There are various types of screening policies and tests with different statistical measure

\footnotetext{
${ }^{1}$ Department of Obstetrics and Gynecology Division of Perinatology Hacettepe University Medical Faculty, Ankara Address of Correspondence: Atakan Tanacan
}

Depermant of Gynecology and
Obstetrics Hacettepe University Faculty
of Medicine Ankara, Turkey
atakantanacan@yahoo.com
31.05.2018
19.06.2018
A.T.: 0000-0001-8209-8248
L.:0000-0002-9735-458X

$\begin{array}{ll}\text { Submitted for Publication: } & 31.05 .2018 \\ \text { Accepted for Publication: } & 19.06 .2018\end{array}$

Orcid No:

D.C.K.: 0000-0003-4484-0549, A.T.: 0000-0001-8209-8248

G.O.:0000-0003-0578-4230, K.L.:0000-0002-9735-458X M.S.B.: 0000-0001-6362-787X

\begin{tabular}{|c|c|}
\hline \multirow{3}{*}{ 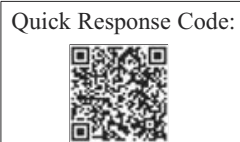 } & Access this article online \\
\hline & $\begin{array}{l}\text { Website: www.gorm.com.tr } \\
\text { e- mail: info@gorm.com.tr }\end{array}$ \\
\hline & DOI:10.21613/GORM.2018.798 \\
\hline
\end{tabular}

How to cite this article: Katlan DC. Tanacan A. Orgul G. Leblebicioglu K. Beksac MS. An Intelligent Prenatal Screening System for the Prediction of Trisomy-21 Using Triple Test Variables: The Hacettepe System. Gynecol Obstet Reprod Med 2019;25(2):67-69 capabilities (1-3). Double test (DT), combined test (CT), triple test (TT), quadruple test (QT), and noninvasive prenatal test (NIPT) using the cell-free fetal DNA are the widely used PS tests (1-3).

Some institutions are still using PS tests based on maternal serum biochemical markers because of their cost-effectiveness $(4,5)$. Different probability algorithms (such as the tri-variate Gaussian algorithm) with various cut-off values are used in routine clinical practice (6). However, some questions remain in the patients' minds regarding the cut-off values and probability concepts in daily applications. They expect easier and better explanations about screening mentality and test results.

Recent technological improvements enable physicians to use artificial intelligent systems (AIS) in clinical decision making (7-9). We have previously reported an artificial intelligent diagnostic system with neural networks to determine genetic disorders and fetal health using the TT biochemical markers (10). Unconjugated estriol (E3), beta-human chorionic gonadotropin $(\beta-\mathrm{hCG})$, and $\alpha$-feto protein (AFP) with gestational week and maternal age were used in the TT (6). The advantage of supervised, unsupervised and hybrid intelligent systems is the flexibility in choosing input variables and goals. Various versions may be created to detect different fetal 
health problems, such as genetic disorders in general, aneuploidies, certain trisomies, or trisomy 21 only.

In this version of supervised AIS (backpropagation learning algorithm), we have used TT variables as input variables to detect "only trisomy 21 " fetuses. This study aimed to introduce an alternative approach (methodology) in the clinical application of TT.

\section{Material and Method}

In this study, we have used a backpropagation learning algorithm (a supervised artificial neural network) to develop an intelligent antenatal screening system (heretofore referred as Hacettepe System) (10). TT variables were used as input variables, while "Down syndrome" (DS) and "non-DS" fetuses were the output of the algorithm. Unconjugated estriol (E3), beta-human chorionic gonadotropin ( $\beta$-hCG), and $\alpha$-feto protein (AFP) with gestational week and maternal age (TT) were used as input variables in training and testing. Multiples of median (MoM) values of the E3, AFP, and $\beta$-hCG were used in this study.

The testing group of Hacettepe system consisted of 97 patients who were found to be high-risk $(>1 / 250)$ in the antenatal screening (TT) and underwent amniocentesis (AC) for fetal karyotyping. The institutional ethics committee of the Hacettepe University (GO 16/690) has approved the study protocol.

\section{Result}

Amniocentesis was performed in 97 pregnancies with "high-risk" TT results $(>1 / 250)$. Fetal karyotyping revealed trisomy 21 in about $9.3 \%(9 / 97)$ of the pregnancies.

Then, the TT variables in our study subjects (97 pregnancies) were used for testing our algorithm. Our algorithm detected 77.8\% (7/9) DS cases. Moreover, all of the normal fetal karyotypes were assigned as normal in the Hacettepe System.

\section{Discussion}

PS is an essential component of antenatal care programs, and different types of tests are used for this purpose $(11,12)$. Maternal blood biochemical markers and "maternal blood cell free fetal DNA" are still used in PS due to their cost-effectiveness $(4,5)$. Classical statistical methods (probability algorithms) are used in DT, CT, and TT, which make patients uncomfortable in terms of understanding their purpose.

The association between low maternal serum unconjugated E3 and AFP concentrations and increased hCG blood levels were already known for a long time (6). TT is still used in some institutions under certain conditions, especially when AFP measurements are necessary. However, the predictive value of TT is not as satisfactory as that of CT and NIPT $(13,14)$.
AIS are widely used in medical applications and decision making in our routine medical practices (7-9). Neural network and learning algorithms broaden our perspectives in the utilization of various test results (7-9). The advantage of learning algorithms is the flexibility in creating various versions using the same input variables of the different patient groups. The limitation of this study is testing the algorithm. The algorithm is only tested using the TT data of high-risk patients detected by the classic TT.

In conclusion, we have developed an intelligent system using the backpropagation learning algorithm (using TT variables) to predict trisomy 21 . Therefore, this study aimed to introduce an alternative, patient-friendly PS test using input variables same as those of TT.

: Acknowledgements: Special thanks to all of the medical staff in perinatology clinic and biochemistry laboratories for their contribution in providing the optimal healthcare for the patients.

No funding was used for this study.

The authors state no conflict of interest.

\section{References}

1. Driscoll DA, Gross S. Prenatal screening for aneuploidy. N Engl J Med. 2009;360(24):2556-62.

2. American College of Obstetricians and Gynecologists. Practice Bulletin No. 27: Clinical Management Guidelines for Obstetrician-Gynecologists. Prenatal diagnosis of fetal chromosomal abnormalities. Obstet Gynecol. 2001;97(5 Pt 1):suppl 1-12.

3. Norton ME, Jelliffe-Pawlowski LL, Currier RJ Chromosome abnormalities detected by current prenatal screening and noninvasive prenatal testing. Obstet Gynecol. 2014;124(5):979-86.

4. Gokcen O, Mehmet D, Emine A, Mehmet A, Sinan BM. An overview of prenatal screening/diagnosis programs for Down syndrome in Turkey. Int J Hum Genet. 2016;16 $(1,2): 29-34$.

5. Okem ZG, Orgul G, Kasnakoglu BT, Cakar M, Beksac MS. Economic analysis of prenatal screening strategies for Down syndrome in singleton pregnancies in Turkey. Eur J Obstet Gynecol Reprod Biol. 2017;219:40-4.

6. Haddow JE, Palomaki GE, Knight GJ, Williams J, Pulkkinen A, Canick JA, et al. Prenatal screening for Down's syndrome with use of maternal serum markers. N Engl J Med. 1992;327(9):588-93.

7. Beksac M, Beksac MS, Tipi VB, Duru HA, Karakas MU, Cakar AN. An artificial intelligent diagnostic system on differential recognition of hematopoietic cells from microscopic images. Cytometry. 1997;30(3):145-50.

8. Beksac MS, Basaran F, Eskiizmirliler S, Erkmen AM, Yorukan S. A computerized diagnostic system for the interpretation of umbilical artery blood flow velocity wave- 
forms. Eur J Obstet Gynecol Reprod Biol. 1996;64(1):3742.

9. Beksac MS, Tanacan A, Bacak HO, Leblebicioglu K. Computerized prediction system for the route of delivery (vaginal birth versus cesarean section). J Perinat Med. 2018;46(8):881-4.

10. Beksac MS, Durak B, Ozkan O, Cakar AN, Balci S, Karakas U, et al. An artificial intelligent diagnostic system with neural networks to determine genetical disorders and fetal health by using maternal serum markers. Eur J Obstet Gynecol Reprod Biol. 1995;59(2):131-6.

11. Boyd PA, Devigan C, Khoshnood B, Loane M, Garne E, Dolk H, et al. Survey of prenatal screening policies in Europe for structural malformations and chromosome anomalies, and their impact on detection and termination rates for neural tube defects and Down's syndrome. BJOG
2008;115(6): 689-96.

12. Dondorp W, de Wert G, Bombard Y, Bianchi DW, Bergmann C, Borry $\mathrm{P}$, et al. Non-invasive prenatal testing for aneuploidy and beyond: challenges of responsible innovation in prenatal screening. Eur J Hum Genet. 2015;23(11):1438-50.

13. Gregg AR, Skotko BG, Benkendorf JL, Monaghan KG, Bajaj K, Best RG, et al. Noninvasive prenatal screening for fetal aneuploidy, 2016 update: a position statement of the American College of Medical Genetics and Genomics. Genet Med. 2016;18(10):1056-65.

14. Chitayat D, Langlois S, Douglas Wilson R, SOGC Genetics Committee; CCMG Prenatal Diagnosis Committee. Prenatal screening for fetal aneuploidy in singleton pregnancies. J Obstet Gynaecol Can. 2011; 33(7): 736-50. 